\title{
Validity and Reliability of the Chronic Respiratory Disease Questionnaire in Elderly Individuals with Mild to Moderate Non-Cystic Fibrosis Bronchiectasis
}

\author{
Domagoj A. Vodanovich ${ }^{a}$ Thomas J. Bicknell $^{a}$ Anne E. Holland ${ }^{\text {b-d }}$ \\ Catherine J. Hillc, e Nola Cecins ${ }^{f-h}$ Sue Jenkins ${ }^{f-h} \quad$ Christine F. McDonald $^{c, e}$ \\ Angela T. Burge $^{b}$ Philip Thompson ${ }^{f, h}$ Robert G. Stirling ${ }^{b}$ \\ Annemarie L. Lee ${ }^{b, c, i}$

\begin{abstract}
a Physiotherapy, Western Health, Footscray, Vic., b Alfred Hospital, ' Institute for Breathing and Sleep,

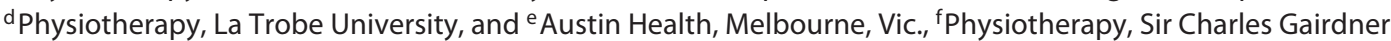

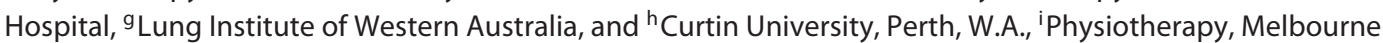
School of Health Sciences, The University of Melbourne, Melbourne, Vic., Australia
\end{abstract}

\section{Key Words}

Bronchiectasis · Quality of life · Reliability · Validity ·

Responsiveness

\begin{abstract}
Background: The chronic respiratory disease questionnaire (CRDQ) is designed to assess health-related quality of life (HRQOL) in chronic respiratory conditions, but its reliability, validity and responsiveness in individuals with mild to moderate non-cystic fibrosis (CF) bronchiectasis are unclear. $\mathbf{O b}$ jectives: This study aimed to determine measurement properties of the CRDQ in non-CF bronchiectasis. Methods: Participants with non-CF bronchiectasis involved in a randomised controlled trial of exercise training were recruited. Internal consistency was assessed using Cronbach's a. Over 8 weeks, reliability was evaluated using intra-class correlation coefficients and Bland-Altman analysis for measures of agreement. Convergent and divergent validity was assessed by correlations with the other HRQOL questionnaires and the Hospital
\end{abstract}

Anxiety and Depression Scale (HADS). The responsiveness to exercise training was assessed using effect sizes and standardised response means. Results: Eighty-five participants were included (mean age $\pm S D, 64 \pm 13$ years). Internal consistency was adequate (>0.7) for all CRDQ domains and the total score. Test-retest reliability ranged from 0.69 to 0.85 for each CRDQ domain and was 0.82 for the total score. Dyspnoea (CRDQ) was related to St George's respiratory questionnaire (SGRQ) symptoms only $(r=0.38)$, with no relationship to the Leicester cough questionnaire (LCQ) or HADS. Moderate correlations were found between the total score of the CRDQ, the SGRQ $\left(r_{s}=-0.49\right)$ and the LCQ score $\left(r_{s}=\right.$ $0.51)$. Lower CRDQ scores were associated with higher anxiety and depression $\left(r_{s}=-0.46\right.$ to -0.56$)$. The responsiveness of the CRDQ was small (effect size 0.1-0.24). Conclusions: The CRDQ is a valid and reliable measure of $\mathrm{HRQOL}$ in mild to moderate non-CF bronchiectasis, but responsiveness was limited.

(c) 2015 S. Karger AG, Basel

\section{KARGER 125}

C 2015 S. Karger AG, Base

0025-7931/15/0902-0089\$39.50/0

E-Mail karger@karger.com

www.karger.com/res
Annemarie L. Lee

Physiotherapy Department

Alfred Health

Commercial Road, Melbourne, VIC 3004

E-Mail Annemarie.Lee@westpark.org 


\section{Introduction}

Non-cystic fibrosis (CF) bronchiectasis is a chronic airway disease that involves the abnormal destruction and dilatation of the bronchi and bronchioles [1]. This may be associated with inflammation and progressive tissue destruction with abnormal lung function [2-5]. Clinically, it is characterised by chronic and commonly purulent sputum expectoration, fatigue, reduced exercise capacity and progressive dyspnoea that can become disabling [2-8]. People with non-CF bronchiectasis frequently experience recurrent acute exacerbations due to a vicious cycle of persistent infection and inflammation $[9,10]$. These symptoms have a significant impact on the patient's health-related quality of life (HRQOL) [11-13].

To date, several questionnaires have been developed to assess HRQOL in chronic respiratory conditions which provide important objective measures in clinical practice, including the St George's respiratory questionnaire (SGRQ), the chronic respiratory disease questionnaire (CRDQ) and, more recently, the quality of life questionnaire - bronchiectasis (QOL-B) $[14,15]$. Both the SGRQ and the CRDQ are disease-specific tools which provide a valid and reliable measure of HRQOL in patients with chronic obstructive pulmonary disease (COPD) [16-19] and those with interstitial lung disease [20]. In non-CF bronchiectasis, the SGRQ, the Leicester cough questionnaire (LCQ) and the QOL-B have been found to be valid and reliable measures of HRQOL [2, 14, 15, 21]. Recent studies exploring the effects of physiotherapy interventions have also applied the CRDQ to assess HRQOL in this population $[22,23]$. In addition, the CRDQ is a recommended tool for assessing the effects of pulmonary rehabilitation on HRQOL [24, 25]; surveys of clinical practice found it to be commonly applied in assessing the effects of this intervention in individuals with non-CF bronchiectasis [26-28]. Despite this use, the measurement properties of the CRDQ in patients with non-CF bronchiectasis and its responsiveness to change are unclear. Therefore, the aim of our study was to examine the role of the CRDQ in measuring HRQOL in patients with non-CF bronchiectasis and, specifically, to determine its reliability, validity and responsiveness.

\section{Materials and Methods}

\section{Study Design}

This is a prospective validation study using data from a larger clinical trial examining the effects of exercise training in non-CF bronchiectasis on HRQOL [23]. The study commenced on April
9, 2009, and concluded on December 12, 2011. Participants were randomised to exercise training or control (no change in management) for 8 weeks and were followed up 6 months after intervention. The study was approved by the Human Research Ethics Committees at each institution. All participants gave written informed consent for the study.

\section{Participants}

Participants had a confirmed diagnosis of non-CF bronchiectasis through high-resolution computed tomography (HRCT) of the chest [29]. Exclusion criteria were other respiratory conditions including COPD [30], asthma [31] or interstitial lung disease as well as any orthopaedic or neurological conditions which prevented the ability to safely undertake exercise or cover a 6-min walk distance (6MWD). Spirometry was measured at baseline according to standard guidelines [32]. Exertional dyspnoea was measured using the modified Medical Research Council Grade (mMRC) [33].

\section{Measurements}

Patients completed four HRQOL instruments, three of which were disease specific. The self-administered CRDQ consists of 20 items and assesses the domains of dyspnoea, fatigue, emotional function and mastery, with a total score ranging from 0 to 100 and higher scores signifying better HRQOL [34]. The SGRQ is a selfadministered tool which consists of 76 items and comprises three components: symptoms, activity and impact, with a total score ranging from 0 to 100 and higher scores indicating a poorer HRQOL $[2,35]$. The LCQ is a 19-item, self-administered questionnaire of three domains measuring the physical, psychological and social impact of chronic cough, with a total severity score ranging from 3 to 21 and lower scores indicating greater impairment [21, 36]. The Hospital Anxiety and Depression Scale (HADS) measured the presence of anxiety or depression across 14 items, with a score of $\geq 11$ indicative of clinically significant anxiety or depression [37]. Functional exercise capacity was measured using $6 \mathrm{MWD}$. Two tests were completed on each assessment occasion to a standardised protocol, with the better of the two tests recorded [38].

\section{Reliability, Validity and Responsiveness}

The internal consistency of the CRDQ was measured using Cronbach's $\alpha$, based on the baseline assessment of the three domains and total score in all participants. For assessment of reliability, the intra-class correlation coefficient $(\mathrm{ICC})_{(2,1)}$ was measured in a group of 43 participants who had no change in management between baseline and the follow-up visit 9 weeks later (controls). A Bland-Altman analysis for the total CRDQ score was used to demonstrate agreement over time. For both Cronbach's $\alpha$ and the ICC, values $>0.7$ were considered acceptable [39].

Using baseline measures of all participants, convergent validity was assessed using total scores and specific domains from the CRDQ, SGRQ and LCQ, with moderate to high correlations expected between total scores, and individual domains of those questionnaires measuring similar constructs. Similar constructs for the CRDQ dyspnoea and fatigue domains were the SGRQ symptoms and activity domains as well as the LCQ physical domain; for the CRDQ emotional function and mastery domains, the SGRQ impact domain, the LCQ psychological domain and the anxiety and depression scores were similar constructs. Discriminant validity 
was tested using the CRDQ domains and total score with lung function (spirometry) and 6MWD. Correlations were calculated using Pearson's correlation coefficient and Spearman's rank correlation as appropriate. Correlations $<0.3$ were considered weak, correlations between 0.3 and 0.5 were moderate, with those $>0.5$ considered strong [39].

Responsiveness was examined in participants who completed 8 weeks of exercise training, with the CRDQ completed prior to commencing exercise training and repeated 1 week following training completion. The responsiveness of the CRDQ was determined by calculating the effect size, which was defined as the ratio of mean change score divided by SD of the baseline score. It was also measured using the standardised response mean, which was the mean change divided by SD of the change score. An effect size of 0.2 is equivalent to a small effect, 0.5 is a medium and 0.8 is a large effect size [39]. For comparison, effect sizes of the SGRQ were also calculated.

\section{Statistical Analysis}

Statistical analysis was performed using SPSS for Windows, version 21.0 (SPSS Inc., Chicago, Ill., USA). Subgroup analysis was measured using unpaired Student's t test and one-way analysis of variance (ANOVA).

\section{Results}

Overall, a total of 85 participants were included in the study. All of them participated in the cross-sectional analyses of internal consistency. Of these, 43 participants were included in the reliability analysis, and 42 participated in the responsiveness analysis. The clinical characteristics are outlined in table 1 . The majority of participants were female $(72 \%)$, with a mean age of 64 years. On average, the participants had mild to moderate disease severity, as indicated by their forced expiratory volume in $1 \mathrm{~s}$ and forced vital capacity (\% predicted; table 1 ).

The summary scores of each of the HRQOL instruments are outlined in table 2. Greater impairment in dyspnoea and fatigue was evident compared to emotional function or mastery according to the CRDQ. Individual responses for the CRDQ and SGRQ covered the entire range of possible scores, with 1 participant demonstrating a floor effect and 1 participant demonstrating a ceiling effect for each domain. Based on the initial validation of the LCQ in bronchiectasis [19], there was a moderate to severe degree of impairment of QOL related to cough. However, the extent of anxiety and depression in these patients appeared to be minimal.

According to the CRDQ, females reported greater fatigue compared to males $(\mathrm{p}=0.008)$, but there was no difference in dyspnoea $(\mathrm{p}=0.31)$, emotional function $(\mathrm{p}=0.93)$ and mastery $(\mathrm{p}=0.86)$. There was no difference
Table 1. Patient characteristics $(\mathrm{n}=85)$

\begin{tabular}{lcc}
\hline & Mean \pm SD & Range \\
\hline Age, years & $64 \pm 13$ & $58-73$ \\
BMI & $24.4 \pm 5.3$ & $20.6-27.7$ \\
FEV $_{1}, \%$ predicted & $73 \pm 21$ & $59-89$ \\
FVC, \% predicted $_{\text {FEV }} /$ FVC & $81 \pm 20$ & $68-97$ \\
mMRC dyspnoea grade & $55 \pm 34$ & $35-82$ \\
6MWD, m & $1.5 \pm 0.7$ & $1-3$ \\
6MWD, \% predicted & $565 \pm 90$ & $508-625$ \\
& $84 \pm 13$ & $78-93$ \\
\hline
\end{tabular}

$\mathrm{BMI}=$ Body mass index $\mathrm{FEV}_{1}=$ forced expiratory volume in $1 \mathrm{~s} ; \mathrm{FVC}=$ forced vital capacity.

Table 2. Baseline HRQOL status scores $(n=85)$

\begin{tabular}{lcc}
\hline & Mean \pm SD & Range \\
\hline CRDQ & & \\
Total & $82.2 \pm 16.8$ & $78.0-101.0$ \\
Dyspnoea & $14.3 \pm 6.5$ & $12.0-20.0$ \\
Fatigue & $15.5 \pm 4.6$ & $13.0-20.5$ \\
Emotional function & $32.3 \pm 8.2$ & $29.0-41.5$ \\
Mastery & $20.3 \pm 4.4$ & $19.0-26.0$ \\
SGRQ & & \\
Total & $37.0 \pm 16.1$ & $27.4-49.7$ \\
Symptoms & $59.3 \pm 22.3$ & $46.6-81.5$ \\
Activity & $42.1 \pm 19.9$ & $29.2-55.6$ \\
Impact & $27.1 \pm 16.7$ & $16.5-38.0$ \\
LCQ & & \\
Total & $14.2 \pm 4.1$ & $12.5-17.4$ \\
Physical & $4.5 \pm 0.9$ & $4.3-5.7$ \\
Psychological & $4.8 \pm 1.4$ & $4.3-6.4$ \\
Social & $4.6 \pm 1.9$ & $4.2-5.5$ \\
HADS & & \\
Anxiety & $4.4 \pm 3.3$ & $2.5-7.0$ \\
Depression & $2.9 \pm 2.7$ & $1.0-5.0$ \\
\hline
\end{tabular}

in the CRDQ domain dyspnoea according to mMRC scores $(p=0.77)$. There was no correlation with age or body mass index in any of the CRDQ domains (all $\mathrm{r}<0.2$, $\mathrm{p}>0.05$; data not shown).

\section{Internal Consistency and Reproducibility}

The internal consistency of the CRDQ was adequate $(\geq 0.70)$ for all four domains and the total score. Cronbach's a coefficient was 0.76 for dyspnoea, 0.85 for fatigue, 0.94 for emotional function and 0.80 for mastery. Of the 43 control participants who performed the CRDQ, 9 weeks apart for test-retest reliability, the ICC demon- 
Table 3. Convergent and discriminant validity $(\mathrm{n}=85)$

\begin{tabular}{|c|c|c|c|c|c|}
\hline & \multicolumn{5}{|l|}{ CRDQ } \\
\hline & dyspnoea & fatigue & emotional function & mastery & total \\
\hline $\mathrm{FEV}_{1}$ (\% predicted) & -0.08 & 0.08 & 0.01 & 0.024 & 0.01 \\
\hline FVC (\% predicted) & -0.04 & 0.08 & -0.07 & -0.003 & -0.02 \\
\hline \multicolumn{6}{|c|}{ LCQ } \\
\hline Total & 0.00 & $0.406^{* *}$ & $0.561^{* *}$ & $0.619^{* *}$ & $0.512^{* *}$ \\
\hline Physical & 0.06 & $0.551^{* *}$ & $0.53^{*}$ & $0.669^{* *}$ & $0.571^{* *}$ \\
\hline Psychological & -0.04 & $0.334^{*}$ & $0.559^{* *}$ & $0.556^{* *}$ & $0.467^{* *}$ \\
\hline Social & 0.098 & 0.177 & 0.170 & 0.188 & 0.153 \\
\hline \multicolumn{6}{|l|}{ SGRQ } \\
\hline Total & 0.28 & $-0.541^{* *}$ & $-0.471^{* *}$ & $-0.685^{* *}$ & $-0.493^{* *}$ \\
\hline Symptoms & $0.38^{*}$ & $-0.319^{*}$ & $-0.342^{*}$ & $-0.559^{* *}$ & $-0.367^{*}$ \\
\hline Activity & 0.215 & $-0.63^{* *}$ & $-0.306^{*}$ & $-0.463^{* *}$ & $-0.346^{*}$ \\
\hline Impact & 0.26 & $-0.383^{*}$ & $-0.521^{* *}$ & $-0.684^{* *}$ & $-0.482^{* *}$ \\
\hline \multicolumn{6}{|l|}{ HADS } \\
\hline Anxiety & 0.004 & $-0.381^{*}$ & $-0.550^{* *}$ & $-0.442^{* *}$ & $-0.459^{* *}$ \\
\hline Depression & -0.14 & $-0.43^{*}$ & $-0.529 * *$ & $-0.602^{* *}$ & $-0.555^{* *}$ \\
\hline $6 \mathrm{MWD}(\mathrm{m})$ & -0.139 & $-0.280^{*}$ & 0.176 & $0.345^{* *}$ & 0.189 \\
\hline mMRC & 0.112 & 0.223 & -0.138 & $-0.301^{*}$ & -0.160 \\
\hline
\end{tabular}

Data are based on Pearson's correlation coefficient or Spearman's rank coefficient. $\mathrm{FEV}_{1}=$ Forced expiratory volume in $1 \mathrm{~s} ; \mathrm{FVC}=$ forced vital capacity. ${ }^{*} \mathrm{p}<0.05 ;{ }^{* *} \mathrm{p}<0.01$.

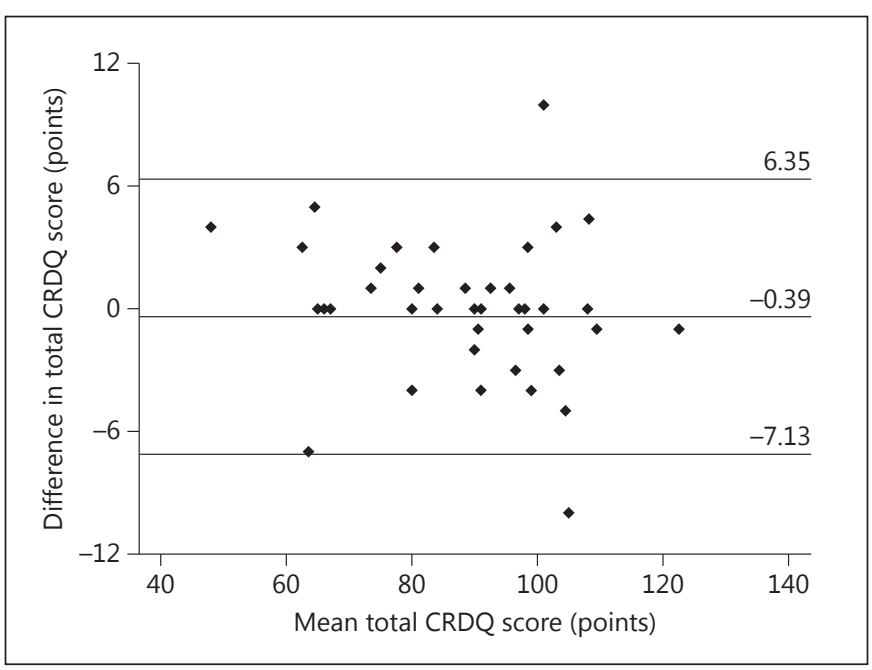

Fig. 1. Bland-Altman plot of the CRDQ total score repeated over 9 weeks in 42 patients with non-CF bronchiectasis.

strated very good internal consistency for the total score (0.82, 95\% CI 0.66-0.90), dyspnoea ( $0.85,95 \%$ CI $0.71-$ $0.92)$, fatigue $(0.69,95 \%$ CI $0.41-0.83)$, emotional function $(0.83,95 \%$ CI $0.69-0.91)$ and mastery $(0.77,95 \%$ CI 0.56-0.88). The Bland-Altman plot of the CRDQ total score is shown in figure 1 . The mean difference after 9 weeks was 0.39 (3.6), with an upper limit of agreement of 6.35 and a lower limit of -7.31 .

\section{Validation}

For convergent validity, the correlation coefficient of the total CRDQ score demonstrated a fair relationship with the total SGRQ score at baseline (table 3). The dyspnoea domain only correlated with SGRQ symptoms, while the fatigue, emotional function and mastery domains were more strongly associated with each of the SGRQ components and total score (table 3). Similarly, there was a fair to moderate relationship between the fatigue, emotional function and mastery domains of the CRDQ and LCQ as well as anxiety and depression.

For discriminant validity, there was no correlation between CRDQ scores and 6MWD or spirometry measures (table 3 ). The $\mathrm{mMRC}$ rating showed only a fair relationship with CRDQ fatigue levels.

\section{Responsiveness: The CRDQ at the Start and End of Exercise Training}

In the 42 participants who undertook exercise training for 8 weeks, there was a significant improvement in the CRDQ domains of dyspnoea $(\mathrm{p}=0.011)$ and fatigue $(\mathrm{p}=$ 
Table 4. Responsiveness of the CRDQ to exercise training $(\mathrm{n}=42)$

\begin{tabular}{lll}
\hline & $\begin{array}{l}\text { Effect size } \\
\text { index }\end{array}$ & $\begin{array}{l}\text { Standardised } \\
\text { response mean }\end{array}$ \\
\hline CRDQ & & \\
Total & 0.32 & 0.24 \\
Dyspnoea & 0.30 & 0.21 \\
Fatigue & 0.16 & 0.13 \\
Emotional function & 0.05 & 0.22 \\
Mastery & 0.02 & 0.10 \\
SGRQ & & \\
Total & 0.25 & 0.37 \\
Symptoms & 0.53 & 0.85 \\
Activity & 0.27 & 0.28 \\
Impact & 0.38 & 0.35 \\
\hline
\end{tabular}

0.04) as well as the SGRQ domains of symptoms ( $\mathrm{p}=$ $0.001)$ and activity $(\mathrm{p}=0.04)$ and the SGRQ total score $(p=0.03)$. The changes in each of the CRDQ component scores were as follows (mean $\pm \mathrm{SD}$ ): dyspnoea $2.0 \pm 9.4$, fatigue $0.76 \pm 5.8$, emotional function $0.5 \pm 2.3$, mastery $-0.12 \pm 6.9$ and total score $2.4 \pm 16.6$. According to both the effect size and standardised response mean, the change in the CRDQ domain of dyspnoea and total score represented a small effect (table 4). In comparison, the SGRQ symptoms, activity and total score demonstrated a small to moderate change according to both methods of analysis.

\section{Discussion}

This is the first study to describe the validity and reliability of the CRDQ in mild to moderate non-CF bronchiectasis. It showed that the CRDQ provides a reliable measure of HRQOL, with good convergent validity in relation to other HRQOL instruments, which have been validated in this patient population. Although able to detect change in an intervention, such as exercise training, the CRDQ was less sensitive to change compared to the SGRQ.

In general, the CRDQ demonstrated an acceptable level of internal consistency, similar to that described in COPD [34, 40-42]. The total score and all domain scores had ICCs $>0.69$, demonstrating that the repeatability of the CRDQ in non-CF bronchiectasis is adequate and compares favourably to previous reports of this questionnaire in patients with COPD [34]. The limits of agreement of the total CRDQ score were less than the known minimal important difference reported in COPD for this questionnaire $[43,44]$; this implies that there was adequate agreement of the CRDQ in this study.

Only a fair relationship was demonstrated between the CRDQ dyspnoea domain and the symptom domain of the SGRQ. This may be related to the overall mild functional impairment of this patient group as indicated by a mean mMRC score of 1 (shortness of breath when hurrying on level ground or walking up a slight hill) and the relatively well-preserved lung function, which were features of this sample population. Dyspnoea of a mild degree appears to have less impact on physical measures, which may account for the lack of correlation between dyspnoea and the SGRQ activity domain. Although it contrasts with a previous report of a strong association between dyspnoea and physical function [2], this may be related to the more severe disease (forced expiratory volume in $1 \mathrm{~s}: 66 \%$ ) evident in the previous study.

In addition, dyspnoea is often a less frequently reported symptom in bronchiectasis [12]. Whilst the dyspnoea domain of the CRDQ evaluates only a single symptom, the symptom domain of the SGRQ evaluates dyspnoea as well as wheeze, cough, sputum production and number of exacerbations [35]. Compared to the CRDQ, which evaluates dyspnoea, fatigue, emotional function and mastery $[17,34]$, the QOL-B, which was specifically developed for bronchiectasis, provides a more detailed review of respiratory symptoms (including dyspnoea) as well as measurement of physical, emotional and social function, role function, vitality, illness perception and treatment burden $[14,15]$. For this reason, identification of the common respiratory symptoms experienced in each individual patient may influence the choice of instrument used to evaluate HRQOL. The QOL-B is readily available, but as a newly devised tool, its use in clinical practice is evolving; in comparison, the CRDQ is currently an established measure of HRQOL within existing pulmonary rehabilitation programs $[22,26-28]$. Although it does not encompass the breadth of symptoms and clinical features like the QOL-B, there is merit in establishing the measurement properties of this tool. Programs such as pulmonary rehabilitation often include a mix of patient populations [22, 26-28]; comparing changes in HRQOL between patient groups following treatment using a tool which is valid and reliable in every population facilitates the clinical interpretation of this intervention.

A key finding of the study was the presence of a moderate to strong relationship between the CRDQ domain fatigue and all domains of the SGRQ, the physical and psychological impact of chronic cough and anxiety and 
depression. Despite patients demonstrating overall mild impairment in cough-related QOL, this high tolerance of cough-related symptoms did not mask the impact of a chronic cough on fatigue in this population. These findings are consistent with a study of patients with moderately severe bronchiectasis, in which significant correlations between the Fatigue Severity Scale and the LCQ physical domain $(\mathrm{r}=-0.56)$ and total score $(\mathrm{r}=-0.50)$ were evident [45]. Sources of systemic fatigue in bronchiectasis are multi-factorial and the relationships demonstrated in the current study suggest that other factors, including the cycle of repetitive infection and inflammation which defines bronchiectasis [1] are possible contributing factors. In addition, the association between fatigue and activity levels suggests that the peripheral muscle dysfunction and deconditioning that have been described in non-CF bronchiectasis $[45,46]$ which is related to reduced physical function $[11,47]$ may also contribute to this clinical characteristic. With fatigue reported in up to $74 \%$ of patients with bronchiectasis $[6,12]$, its psychological impact reflected by levels of anxiety and depression may be critical to consider in some patients.

The moderate to strong correlations between the CRDQ domains of emotional function and mastery to all domains of the SGRQ and LCQ suggests that the key clinical features of cough, sputum production, breathlessness, wheeze, fatigue and impaired exercise tolerance directly impact patients' ability to cope with their chronic condition. The exception to this is the social impact of chronic cough, with no relationship between the LCQ social score and the CRDQ domains of emotional function or mastery. This suggests that as an accurate assessment of impaired social function secondary to chronic cough, the LCQ is preferable to the CRDQ to quantify this impact [21]. Knowledge of these relationships may be useful for clinicians instituting treatment approaches to manage these clinical consequences of non-CF bronchiectasis and perhaps to consider evaluating not only the effect of these interventions on signs and symptoms, but also on the psychological function and levels of anxiety and depression $[48,49]$ in these patients.

The lack of a relationship between exercise capacity and CRDQ domains differs to earlier reports, in which measures of HRQOL and field walking tests were strongly related $[2,50]$. The likely reason for the findings in our study is the overall mild functional impairment of our patients, with the $6 \mathrm{MWD}$ being $84 \%$ of the predicted normal [51]. Although mild compared to previous reports $[52,53]$, the baseline $6 \mathrm{MWD}$ and $\mathrm{mMRC}$ values are equivalent to those reported in patients enrolled in previ- ous pulmonary rehabilitation programs [54]. Disease severity did not correlate with CRDQ HRQOL, which is consistent with spirometry measures not being an independent predictor of 6MWD [50]. Analysis of disease severity of bronchiectasis is often better suited to HRCT scoring [29]. As this was not included in the current study, further analysis of the relationship between disease severity based on HRCT and this HRQOL instrument is required.

The CRDQ was less responsive to improvements with exercise training than the SGRQ. This may be attributable to the significant change in dyspnoea and fatigue following exercise training but the lack of effect on emotional function or mastery in these participants [23]. In contrast, there was a significant difference in SGRQ symptoms, activity and total score. The lack of change in emotional function and mastery is likely to be due to the well-preserved levels at baseline. Despite the influence of these participant baseline characteristics, it suggests that the CRDQ may not be the most sensitive measure for assessing the change in HRQOL following this intervention. In the absence of a definition of the minimal important difference for HRQOL scores in bronchiectasis, the use of a distribution-based approach in this study reflects one dimension of responsiveness. Future studies incorporating a patient perception of change following exercise training or other interventions are necessary to gain a more indepth analysis of the responsiveness of the CRDQ.

There are limitations in this study. Firstly, the overall disease severity of the patients was limited to mild to moderate non-CF bronchiectasis. For this reason, our results only apply to patients with a similar disease severity and mild functional capacity; further confirmation is required in patients experiencing more severe lung disease and those with moderate and severe impairment in functional capacity. Further examination of the discriminant validity of the CRDQ with respect to disease severity is necessary. In addition, bronchiectasis is not only a disease of adults; it also affects children, adolescents and younger adults $[55,56]$. The age range in this sample population was $58-73$ years. While the CRDQ may not be a suitable tool for assessing HRQOL in children with bronchiectasis, its validity and reliability in adolescents and adults aged $<58$ years requires further analysis. The relatively small number of participants may have influenced the effect size of the CRDQ following exercise training. For this reason, the responsiveness to exercise training should be examined in a larger group of patients.

In conclusion, the CRDQ, although not specifically designed for non-CF bronchiectasis, provides a reliable and 
valid reflection of HRQOL in elderly individuals with this condition with mild to moderate disease severity. This, together with its ease of use enhances the clinical appeal and application of the CRDQ. Confirmation of the responsiveness of the CRDQ to the effects of interventions other than exercise training requires further study.

\section{Acknowledgements}

This research was supported by The Alfred Foundation Research Trust, The Institute for Breathing and Sleep, the Sir Charles Gairdner Hospital Research Fund and the Alfred Physiotherapy Research Grant. The authors would like to acknowledge Holly Landers (blinded assessor) at one site.

\section{References}

1 Barker A: Bronchiectasis. N Engl J Med 2002; 346:1383-1393.

-2 Wilson C, Jones P, O'Leary C, Cole P, Wilson R: Validation of the St George's Respiratory Questionnaire in bronchiectasis. Am J Respir Crit Care Med 1997;156:536-541.

-3 Martinez-Garcia M, Perpina-Tordera M, Soler-Cataluna J, Roman-Sanchez P, Lloris-Bayo A, Gonzalex-Molina A: Dissociation of lung function, dyspnea ratings and pulmonary extension in bronchiectasis. Respir Med 2007; 101:2248-2253.

4 Martinez-Garcia M, Soler-Cataluna J, Perpina-Tordera M, Roman-Sanchez P, Soriano S: Factors associated with lung function decline in adult patients with stable non-cystic fibrosis bronchiectasis. Chest 2007;132:15651572.

5 Koulouris N, Retsou S, Kosmas E, Dimakou K, Malagari K, Mantzikopoulos G, Koutsoukou A, Milic-Emili J, Jordanoglou, J: Tidal expiratory flow limitation, dyspnoea and exercise capacity in patients with bilateral bronchiectasis. Eur Respir J 2003;21:743-748.

6 King P, Holdsworth S, Vallanueva E, Vallanueva E, Gallagher M, Holmes P: Outcome in adult bronchiectasis. COPD 2005;2:27-34.

7 Hester L, MacFarlane J, Tedd H, Jary H, McAlinden P, Rostron L, Small T, Newton JL, De Soyza A: Fatigue in bronchiectasis. Oxford Med J 2012;105:235-240.

-8 Gale N, Bolton C, Duckers J, Enright S, Cockcroft J, Shale D: Systemic comorbidities in bronchiectasis. Chron Respir Dis 2012,9:231238.

-9 Seitz A, Olivier K, Steiner C, Montes de Oca R, Holland S, Prevots R: Trends and burden of bronchiectasis - associated hospitalisations in the United States, 1993-2006. Chest 2012; 138:944-949.

10 Weycker D, Edelsberg J, Oster G, Tino G: Prevalence and economic burden of bronchiectasis. Clin Pulmon Med 2005;12:205-209.

11 Martinez-Garcia M, Perpina-Tordera M, Roman-Sanchez P, Soler-Cataluna J: Quality of life determinants in patients with clinically stable bronchiectasis. Chest 2005;128:739745.

12 King P, Holdsworth S, Freezer N, Villanueva E, Holmes P: Characterisation of the onset and presenting clinical features of adult bronchiectasis. Respir Med 2006;100:2183-2189.

Validity of Quality of Life Questionnaire in Non-CF Bronchiectasis
13 Olveira C, Olveira G, Gaspar I, Dorado A, Cruz I, Soriguer F, Quittner AL, Espildora F: Depression and anxiety symptoms in bronchiectasis: associations with health-related quality of life. Qual Life Res 2013;22:597-605.

14 Quittner AL, Marciel KK, Salathe MA, O’Donnell AE, Gotfried MH, Ilowite JS, Metersky, ML, Flume PA, Lewis SA, McKevitt M, Montgomery BA, O'Fiordan TG: Preliminary quality of life questionnaire-bronchiectasis: a patient-reported outcome measure for bronchiectasis. Chest 2014;146:437-448.

15 Quittner AL, O'Donnell AE, Salathe MA, Lewis SA, Li X, Montgomery AB, O’Riordan TG, Barker AF: Quality of Life QuestionnaireBronchiectasis: final psychometric analyses and determination of minimal important difference scores. Thorax 2015;70:12-20.

16 Guyatt G, Berman L, Townsend M, Pugsley S, Chambers L: A measure of quality of life for clinical trials in chronic lung disease. Thorax 1987;42:773-778.

17 Wijkstra P, Tenvergert E, VanAltena R, Otten V, Postma D, Krann J, Koëter GH: Reliability and validity of the Chronic Respiratory Questionnaire (CRQ). Thorax 1994;49:465-467.

18 Lacasse Y, Wong E, Guyatt G: A systematic overview of the measurement properties of the Chronic Respiratory Questionnaire. Can Respir J 1997;4:131-139.

19 Harper R, Brazier J, Waterhouse J, Walters S, Jones N, Howard P: Comparison of outcome measures for patients with chronic obstructive pulmonary disease (COPD) in an outpatient setting. Thorax 1997;52:879-887.

20 Chang J, Curtis J, Patrick D, Raghu G: Assessment of health-related quality of life in patients with interstitial lung disease. Chest 1999;116:1175-1182.

21 Murray M, Turnbull K, MacQuarrie S, Pentland J, Hill A: Validation of the Leicester Cough Questionnaire in non-cystic fibrosis bronchiectasis. Eur Respir J 2009;34:125-131.

22 Ong H, Lee A, Hill C, Holland A, Denehy L: Effects of pulmonary rehabilitation in bronchiectasis: a retrospective study. Chron Respir Dis $2011 ; 8: 21-30$.

23 Lee A, Hill C, Cecins N, Jenkins S, McDonald CF, Burge AT, Rautela L, Stirling RG, Thompson PJ, Holland AE: The short and long term effects of pulmonary rehabilitation in patients with non-cystic fibrosis bronchiectasis: a randomised controlled trial. Respir Res 2014;15:44.
24 Spruit MA, Singh SJ, Garvey C, et al; ATS/ERS Task Force on Pulmonary Rehabilitation: An official American Thoracic Society/European Respiratory Society statement: key concepts and advances in pulmonary rehabilitation. Am J Respir Crit Care Med 2013;188:e13-e64.

$\checkmark 25$ Nici L, Donner C, Wouters E, ZuWallack R Ambrosino N, Bourbeau J, Carone M, Celli B, Engelen M, Fahy B, Garvey C, Goldstein R, Gosselink R, Lareau S, MacIntyre N, Maltais F, Morgan M, O'Donnell D, Prefault C, Reardon J, Rochester C, Schols A, Singh S, Troosters T; ATS/ERS Pulmonary Rehabilitation Writing Committee. The American Thoracic Society/European Respiratory Society statement on pulmonary rehabilitation. Am J Respir Crit Care Med 2006;173:1390-1413.

26 Johnston C, Maxwell L, Alison J: Pulmonary rehabilitation in Australia: a national survey. Physiotherapy 2011;97:284-290.

27 O’Neill B, Elborn J, MacMahon J, Bradley J: Pulmonary rehabilitation and follow-on services: a Northern Ireland survey. Chron Respir Dis 2008;5:149-154.

28 Brooks D, Sottana R, Bell B, Hanna M, Laframboise L, Selvanavagarajah S, Goldstein RS: Characterization of pulmonary rehabilitation programs in Canada in 2005. Can Respir J 2007;14: 87-92.

29 Bhalla M, Turcios N, Aponte V, Jenkins M, Leitman B, McCauley D, Naidich DP: Cystic fibrosis: scoring system with thin-section CT. Radiology 1999;179:783-788.

30 Global Initiative for Chronic Obstructive Lung Disease. Global strategy for the diagnosis, management and prevention of COPD. www.goldcopd.org. 2013 (accessed May 27, 2013).

-31 Bousquet J, Clark T, Hurd S: GINA guidelines for asthma and beyond. Allergy 2007;62:102112.

32 Miller M, Hankinson J, Brusasco V, et al; ATS/ERS Task Force: Standardisation of spirometry. Eur Respir J 2005;26:319-338.

-33 Mahler D, Wells C: Evaluation of clinical methods for rating dyspnea. Chest 1988;93: 580-586.

34 Williams J, Singh S, Sewell L, Guyatt G, Morgan M: Development of a self-reported Chronic Respiratory Questionnaire (CRQ-SR). Tho$\operatorname{rax} 2001 ; 56: 954-959$. 
-35 Jones P, Quirk F, Baveystock C, Littlejohns P: A self-complete measure of health status for chronic airflow limitation. The St George's Respiratory Questionnaire. Am Rev Respir Dis 1992;145:1321-1327.

- 36 Birring S, Prudon B, Carr A, Singh SJ, Morgan MD, Pavord ID: Development of a symptom specific health status measure for patients with chronic cough: Leicester Cough Questionnaire (LCQ). Thorax 2003;58:339-343.

- 37 Zigmond A, Snaith R: The hospital anxiety and depression scale. Acta Pyschiatrica Scand 1983;67:361-370.

38 ATS Committee on Proficiency Standards for Clinical Pulmonary Function Laboratories: ATS statement: guidelines for the six-minute walk test. Am J Respir Crit Care Med 2002; 166:111-117.

39 Portney LG, Watkins MP: Foundations of Clinical Research. Applications to Practice, ed 3. Pearson Prentice Hall, Upper Saddle River, 2009.

40 Tsai C, Hodder R, Page J, Cydulka R, Rowe B, Camargo $C$ Jr: The short-term chronic respiratory disease questionnaire was a valid, reliable and responsive quality-of-life instrument in acute exacerbations of chronic obstructive pulmonary disease. J Clin Epidemiol 2008;61: 489-497.

41 Schünemann HJ, Griffith L, Jaeschke R, Goldstein R, Stubbing D, Austin P, Guyatt GH: A comparison of the original chronic respiratory questionnaire with a standardised version. Chest 2003;124:1421-1429.
42 Schünemann HJ, Goldstein R, Mador MJ, McKim D, Stahl E, Puhan M, Griffith LE, Grant B, Austin P, Collins R, Guyatt GH: A randomised trial to evaluate the self-administered standardised chronic respiratory questionnaire. Eur Respir J 2005;25:31-40.

43 Jaeschke R, Singer J, Guyatt G: Measurement of health status. Ascertaining the minimal clinically important difference. Control Clin Trial 1989;10:407-415.

44 Jones P: Interpreting thresholds for a clinically significant change in health status in asthma and COPD. Eur Respir J 2002;19:398_404.

45 Ozalp O, Inal-Ince D, Calik E, Vardar-Yagli N, Saglam M, Savci S, Arikan H, Bosnak-Guclu M, Coplu L: Extrapulmonary features of bronchiectasis: muscle function, exercise capacity, fatigue and health status. Multidiscip Respir Med 2012;7:3

46 Alves de Camargo A, Amaral T, Rached S, Athanazio RA, Lanza FC, Sampaio LM, de Carvalho CR, Cukier A, Stelmach R, Dal Corso $S$ : Incremental shuttle walking test: a reproducible and valid test to evaluate exercise tolerance in adults with non-cystic fibrosis bronchiectasis. Arch Phys Med Rehabil 2013; 95:892-899.

-47 Nicotra M, Fivera M, Dale A, Shepherd R, Carter R: Clinical, pathophysiologic and microbiologic characterisation of bronchiectasis in an aging cohort. Chest 1995;108:955961.

48 O'Leary C, Wilson C, Hansell D, Cole P, WIlson R, Jones P: Relationship between psychological well-being and lung health status in patients with bronchiectasis. Respir Med 2002:96:686-692.
9 Moreno G, Vasconcelos F, Cisneros C, Gomez-Punter R, Segrelles C, Ancochea J: Presence of anxiety and depression in patients with bronchiectasis unrelated to cystic fibrosis. Arch Bronconeumol 2013;49:415-420.

50 Lee AL, Button BM, Ellis SJ, Stirling RG, Wilson JW, Holland AE, Denehy L: Clinical determinants of the 6-minute walk test in nonCF bronchiectasis. Respir Med 2009;103: 780-785.46.

51 Jenkins S, Cecins N, Camarri B, Williams C, Thompson P, Eastwood P: Regression equations to predict 6-minute walk distance in middle-aged and elderly adults. Physiother Theory Pract 2009;25:516-522.

52 Zan Zellar M, Caetano P, Amorim A, Viana P, Martins P, Gaspar L, Hespanhol V, Gomes I: Pulmonary rehabilitation in patients with bronchiectasis: pulmonary function, arterial blood gases and the 6-minute walk test. J Cardiopulm Rehabil Prev 2012;32:278-283

53 Mandal P, Sidhu M, Kope L, Pollock W, Stevenson LM, Pentland JL, Turnbull K, MacQuarrie S, Hill AT: A pilot study of pulmonary rehabilitation and chest physiotherapy versus chest physiotherapy alone in bronchiectasis. Respir Med 2012;106:1647-1654.

54 Newall C, Stockley R, Hill S: Exercise training and inspiratory muscle training in patients with bronchiectasis. Thorax 2005;60:943-948.

55 Redding GJ: Bronchiectasis in children. Pediatr Clin North Am 2009;56:157-171.

56 Karadag B, Karakoc F, Ersu R, et al: Non-cystic fibrosis bronchiectasis in children: a persistent problem in developing countries. Respiration 2005;72:233-238. 